\title{
Involvement of epithelial-mesenchymal transition in adenoid cystic carcinoma metastasis
}

\author{
KOTARO ISHII, MIYUKI SHIMODA, TSUYOSHI SUGIURA, KATSUHIRO SEKI, MIHO TAKAHASHI, \\ MASAKAZU ABE, RYOSUKE MATSUKI, YOSHIKO INOUE and KANEMITSU SHIRASUNA
}

Department of Oral and Maxillofacial Surgery, Graduate School of Dental Science, Kyushu University, Fukuoka, Japan

Received November 11, 2010; Accepted December 30, 2010

DOI: 10.3892/ijo.2011.917

\begin{abstract}
The high frequencies of recurrence and distant metastasis of adenoid cystic carcinoma (AdCC) are significant obstacles for the long-term cure of patients with AdCC and emphasize the need for better understanding of the biological factors associated with these outcomes. To identify proteins that mediate AdCC metastasis, we established three AdCC cell lines expressing green fluorescent protein (GFP) from the ACCS cell line using orthotopic transplantation and in vivo selection in nude mice: Parental ACCS-GFP, highly tumorigenic ACCS-T GFP and metastatic ACCS-M GFP. ACCS-GFP and ACCS-M GFP were subjected to DNA microarray analysis and the results were used for data mining studies. DNA microarray analysis revealed significantly altered biological processes in the ACC-M GFP cells, including events related to cell adhesion (three categories) and signaling (three categories). In particular, a significant down-regulation of cell adhesion molecules, such as cadherins and integrin subunits was observed. The loss of E-cadherin and integrins and the gain of vimentin in ACCS-M GFP cells were confirmed by immunoblotting. These results suggest that epithelial-mesenchymal transition (EMT) is a putative event in AdCC metastasis that induces tumor cell dissemination from the primary tumor site. In summary, in this study we established a useful nude mouse metastasis model which will enable further AdCC metastasis research and clinical treatment trials and we also provide evidence that EMT is significantly involved in the AdCC metastatic process.
\end{abstract}

Correspondence to: Dr Tsuyoshi Sugiura, Department of Oral and Maxillofacial Surgery, Graduate School of Dental Science, Kyushu University, 3-1-1 Maidashi, Higashi-ku, Fukuoka 812-8582, Japan E-mail: sugiura@dent.kyushu-u.ac.jp

Abbreviations: AdCC, adenoid cystic carcinoma; ECM, extracellular matrix; EMT, epithelial-mesenchymal transition; GFP, green fluorescent protein

Key words: adenoid cystic carcinoma, metastasis, epithelialmesenchymal transition, DNA microarray

\section{Introduction}

Adenoid cystic carcinoma (AdCC) is one of the most common malignant tumors of the salivary glands and is characterized by unique clinical features and behavior. Typically, AdCC grows slowly, but spreads relentlessly into adjacent tissues. The frequencies of recurrence and distant metastasis of AdCC are markedly high, with 40-60\% of AdCC patients developing distant metastases in the lungs, bone and soft tissues (1-4). Therefore, distant failure remains a significant obstacle to the long-term cure of patients with AdCC and emphasizes the need for a better understanding of the biological factors associated with AdCC distant metastasis.

The metastatic spread of tumor cells is a complex multistep process. In order to metastasize, tumor cells first need to invade through a basement membrane, detach from the primary tumor mass, enter the circulation, and travel to a distant secondary site where they expand rapidly (5-7). Each of these steps is essential and requires interactions between tumor cells and their microenvironment (8). Unlike common malignant tumors, AdCC cells produce large amounts of extracellular matrix (ECM), consisting of collagen, elastin, basal lamina components and mucopolysaccharides (9). These ECM components can accumulate in intercellular spaces, resulting in the formation of a pseudocyst, which is the characteristic architecture of AdCC (10). Consequently, as AdCC cells can become surrounded by their own ECM, in addition to normal host connective tissue, the mechanisms of invasion and metastasis of AdCC cells are unique from those of other malignant tumors of the oral cavity, particularly in the interaction with the ECM.

In a previous study, we demonstrated that AdCC cells can degrade considerable amounts of mesenchymal-derived ECM, mainly via the uPA-plasmin cascade (10). Moreover, the migration responses of all AdCC cell lines to ECM, particularly types I and IV collagen, are significantly stronger than those of squamous cell carcinoma (SCC) cell lines, even though both cell types generally express similar patterns of integrin subunits (11). In addition, anti- $\alpha_{2}$ integrin antibodies significantly and exclusively inhibit the enhanced migration of AdCC cells to collagen (12). Although these findings related to ECM degradation and migration were obtained using in vitro invasion models, in order to investigate the mechanisms 
of invasion and metastasis of AdCC, an in vivo model would be required.

In this study, we established a highly metastatic subline from the AdCC cell line, ACCS, using orthotopic transplantation in the nude mouse. The derived metastatic and parental cell lines were then subjected to DNA microarray analysis with 54,000 gene probes. We report the results of data mining analysis used to identify uniquely expressed genes in metastatic cells, which were validated using ACCS cell lines. Both the computational and experimental validation highlight the biological alterations associated with metastatic ACCS cells.

\section{Materials and methods}

Cells and culture. In a preliminary experiment, four AdCC cell lines were tested for tumorigenicity: ACCS (9-12), ACCT, and $\mathrm{ACCH}$, which were established in our laboratory, and Acc-3 (13), which was established at the Shanghai Second Medical University. These cell lines were maintained in Dulbecco's Modified Eagle's Medium (DMEM; SigmaAldrich, St. Louis, MO, USA) supplemented with $10 \%$ fetal bovine serum (FBS; Filton Pty, Brooklyn, Australia), $2 \mathrm{mM}$ L-glutamine, penicillin $\mathrm{G}$ and streptomycin in a $5 \% \mathrm{CO}_{2}$ incubator at $37^{\circ} \mathrm{C}$.

Plasmid and transfection. To detect the local growth and metastasis of inoculated cells in mice, ACCS cells were transfected with the pEGFP-N1 vector (Clontech, Palo Alto, CA, USA) using the FuGENE 6 transfection kit (Roche Diagnostics, Indianapolis, IN, USA) according to the manufacturer's instructions. Colonies that exhibited resistance to geneticin (G418, Sigma-Aldrich) were pooled from the individual transfection experiments. In order to obtain cells that homogeneously expressed green fluorescent protein (GFP) clones, a pool of geneticin-resistant colonies was selected using green fluorescence (ACCS-GFP). The selected cells were maintained in DMEM containing 10\% FBS and $1 \mu \mathrm{g} / \mathrm{ml}$ geneticin.

ACCS metastatic orthotopic implantation mouse model and in vivo selection. The animal experimental protocols were approved by the Animal Care and Use Committee of Kyushu University. Eight-week-old female athymic nude mice (BALBcAJcl-nu) were purchased from Kyudo (Fukuoka, Japan). The mice were housed in laminar flow cabinets under specific pathogen-free conditions in facilities approved by Kyushu University. For the experimental metastasis studies, $1 \times 10^{6}$ cells in $40 \mu 1$ phosphate-buffered saline (PBS) were injected into the tongue using a syringe with a 27-gauge disposable needle (TOP Plastic Syringe, Tokyo, Japan) under intraperitoneal diethyl ether anesthesia. The primary tumor volumes were measured weekly, calculated as the length $x$ width $\mathrm{x}$ thickness, and mice were sacrificed when the primary tumor volume reached $100 \mathrm{~mm}^{3}$. After sacrifice, the tongue, cervical lymph nodes, lungs and liver were observed macroscopically. Tumors and the metastasis of GFP-transfected clones were also visualized macroscopically under light excitation. After visualization, the primary tumors and metastatic sites were examined pathologically and immunohistochemically.
Primary AdCC tumors were cultured on plastic tissue culture dishes using an explant cell culture method. Cloned cell lines from the primary lesion were then re-injected into the tongues of nude mice using an identical method and the process was repeated to select a metastatic phenotype (in vivo selection).

Evaluation of tumor dissemination from the primary cancer nest. Tumor dissemination potential from the primary cancer nest was evaluated by an in vitro invasion assay, as described previously (14). Briefly, $1 \times 10^{6}$ of the ACCS subline cells were pelleted and re-suspended in $10 \mu \mathrm{l}$ of collagen type-I gel to form a solid cell cluster. The collagen-embedded tumor cell pellets were allowed to solidify for $30 \mathrm{~min}$ at $37^{\circ} \mathrm{C}$ in a $100-\mu 1$ microcentrifuge tube. The pellets were then embedded in collagen type I-gel containing non-labeled fibroblasts $\left(1 \times 10^{5}\right.$ cells $/ \mathrm{ml}$ ) and solidified. Growth medium was placed over the collagen gels, and the cells were cultured in a $5 \% \mathrm{CO}_{2}$ incubator at $37^{\circ} \mathrm{C}$. The grade of tumor dissemination from the tumor cell pellet (mimic for the primary tumor nest) was evaluated by measuring the distance of all cells from the edge of the nest in five randomly selected standardized rectangular light fields $(500 \times 100 \mu \mathrm{m})$ under a fluorescence microscope (BZ-8000; Keyence, Osaka, Japan), and the values were summed. The evaluation was performed twice daily for seven days.

DNA microarray analysis. Total RNA was prepared using TRIzol Reagent (GibcoBRL Life Technologies, Rockville, MD, USA). RNA samples were prepared from the ACCS-GFP cell lines and the metastatic clone ACCS-M GFP, which was established after the fourth round of in vivo selection. DNA microarray hybridization and scanning were performed using the Affymetrix GeneChip HG-U133A plus 2.0 array. Statistical analysis (Student's t-test) and a fold-change filter $(>3.0)$ were performed sequentially to select the most significant genes. Using the Gene Ontology Analysis feature of GeneSpring GX software, the significantly expressed genes were categorized into specific biological processes defined in the Gene Ontology Database. Each process that contained significantly expressed genes was ranked according to significance using the P-value overlap of experimentally significant genes with known genes in each biological process.

Immunoblot analysis. In order to visualize cell adhesion molecules, cells were rinsed with PBS and lysed in ice-cold buffer [50 mM Tris- $\mathrm{HCl}(\mathrm{pH} 7.5), 150 \mathrm{mM} \mathrm{NaCl}, 2 \mathrm{mM}$ EGTA and $1 \%$ Triton X-100] containing protease inhibitor cocktail (Sigma-Aldrich). In some experiments, cells were fractionated using an ultracentrifuge, as described previously $(15,16)$. Briefly, cells were harvested in $1 \mathrm{ml}$ ice-cold PBS containing protease inhibitors, and cell structures were destroyed using an ultrasonic sonicator for $2 \mathrm{~min}$, followed by 10 passages through a 27 -gauge needle. The nuclei were removed in two 15-min centrifugation steps at $500 \mathrm{x}$ g. The resulting supernatant was centrifuged at $12,500 \mathrm{x}$ g to yield a crude cytosolic fraction (supernatant) and a membrane pellet comprising of the mitochondria, endoplasmic reticulum and plasma membrane (pellet). The crude cytosolic fraction was then centrifuged for $30 \mathrm{~min}$ at $100,000 \mathrm{x}$ g to yield a pure 
Table I. Tumorigenicity and metastatic potential of the ACCS sublines.

\begin{tabular}{lcccc}
\hline \multirow{2}{*}{ Cell line } & Tumorigenicity & & \multicolumn{2}{c}{ Metastasis } \\
\cline { 2 - 2 } \cline { 5 - 5 } \cline { 5 - 5 } & $\begin{array}{c}\text { Tumor/ } \\
\text { mice (\%) }\end{array}$ & & $\begin{array}{c}\text { Metastatic LN/ } \\
\text { mice (\%) }\end{array}$ & $\begin{array}{c}\text { Lung metastasis/ } \\
\text { mice (\%) }\end{array}$ \\
\hline ACCS & $1 / 6(16.7)$ & & ND & ND \\
ACCS GFP & $4 / 18(22.2)$ & & $0 / 4(0)$ & $0 / 4(0)$ \\
ACCS-T GFP & $16 / 16(100)$ & & $8 / 16(50)$ & $5 / 16(31.3)$ \\
ACCS-M GFP & $9 / 9(100)$ & & $9 / 9(100)$ & $6 / 9(66.7)$ \\
\hline
\end{tabular}

LN, lymph node; ND, not detected.

cytosolic fraction. The membrane pellet was re-suspended in $0.5 \mathrm{ml} 1 \%$ Triton lysis buffer to solubilize the membranes and the embedded or associated proteins.

The protein content of the lysates and fractionated samples was quantified using a protein assay kit (Bio-Rad Laboratories, CA, USA). Equal amounts of protein from each sample were re-suspended in SDS sample buffer [10\% SDS, $62.5 \mathrm{mM}$ Tris- $\mathrm{HCl}(\mathrm{pH} 6.8)$ and 50\% glycerol]. Prior to electrophoresis, reduced samples were adjusted to $5 \%$ (v/v) 2-mercaptoethanol and boiled for $5 \mathrm{~min}$. The samples were separated on 7.5 or $12.5 \%$ SDS-polyacrylamide gels and transferred electrophoretically onto nitrocellulose membranes (Bio-Rad Laboratories). After blocking with 5\% skimmed milk in Tris-buffered saline containing $0.1 \%$ Tween-20 (TBS-T), the membranes were incubated overnight with primary antibodies at $4^{\circ} \mathrm{C}$, followed by horseradish peroxidase-conjugated secondary antibodies (DAKO, Carpentaria, CA, USA) for $1 \mathrm{~h}$. The bound antibodies were visualized using ECL immunoblotting detection reagents (Amersham Pharmacia Biotech, UK).

The primary antibodies used for immunoblotting were as follows: Mouse monoclonal antibodies against integrin $\alpha 1$
(MAB1973), integrin $\alpha 3$ (MA2290) and integrin $\beta 1$ (MAB2247), and rabbit polyclonal antibody against integrin $\alpha 4$ (AB1924), were purchased from Chemicon International (Temecula, CA, USA); rabbit polyclonal antibodies against integrin $\alpha 2$ (sc-9089), integrin $\alpha 6$ (sc-13542) and integrin $\alpha 5$ (sc-10729), and mouse monoclonal antibody against vimentin (V9), were purchased from Santa Cruz Biotechnology; mouse monoclonal antibody against E-cadherin was purchased from BD Transduction Laboratories (Franklin Lakes, NJ); rabbit polyclonal antibody against $\beta$-catenin was purchased from Upstate (Temecula, CA, USA); and mouse monoclonal antibody against $\beta$-actin (A5316) and rabbit polyclonal antibody against connexin 43 (C6219) were purchased from Sigma-Aldrich.

\section{Results}

In the preliminary experiment, four $\mathrm{AdCC}$ cell lines were tested for tumorigenicity: ACCS, ACCT, ACCH and Acc-3. None of these cell lines were tumorigenic when $10^{6}$ cells were injected into the tongues of nude mice. As we identified a tumor mass in the tongue of only 1 of the 6 nude mice at 13 weeks after injection of the ACCS cells, the ACCS cell line was selected and used for subsequent studies on tumorigenicity and metastasis.

In vivo selection of a tumorigenic and metastatic AdCC cell line. The parental cell line ACCS and the GFP-transfected subline ACCS-GFP displayed similar morphologies, growth rates, and tumorigenicities, both in vitro and in vivo. Similar to the parental ACCS, the tumorigenicity of ACCS-GFP cells was low (22.2\% incidence, Table I). In the ACCS-GFP cells, tumor formation in the tongue injected with tumor cells was clearly observed under excitation light (Fig. 1A and B), while green fluorescence was not observed in the absence of tumors. Approximately 7-19 weeks after inoculating $10^{6}$ ACCS-GFP cells, the tumor masses reached sizes of $80-140 \mathrm{~mm}^{3}$ in 4 out of 18 mice. Therefore, we performed in vivo selection of
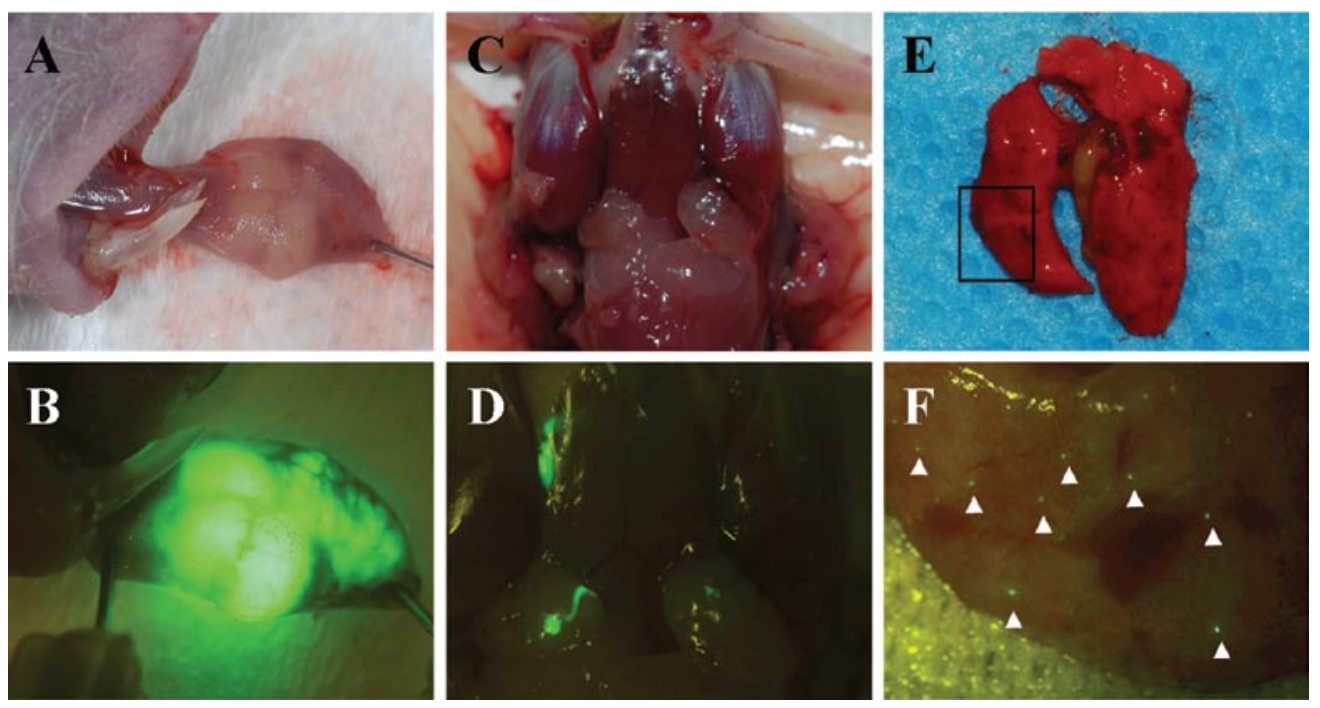

Figure 1. Detection of tumor and metastasis by GFP. Tongues (A and B), lymph nodes (C and D) and lungs (E and F) of nude mice injected with ACCS-M GFP cells were examined to detect tumors or metastases. Observations with the naked eye (A, C and E) and the excitation of GFP (B, D and F) are shown. Sites of lung metastasis are labeled with arrowheads. Note that GFP enables the detection of micro-metastasis in the lymph nodes and lungs. 


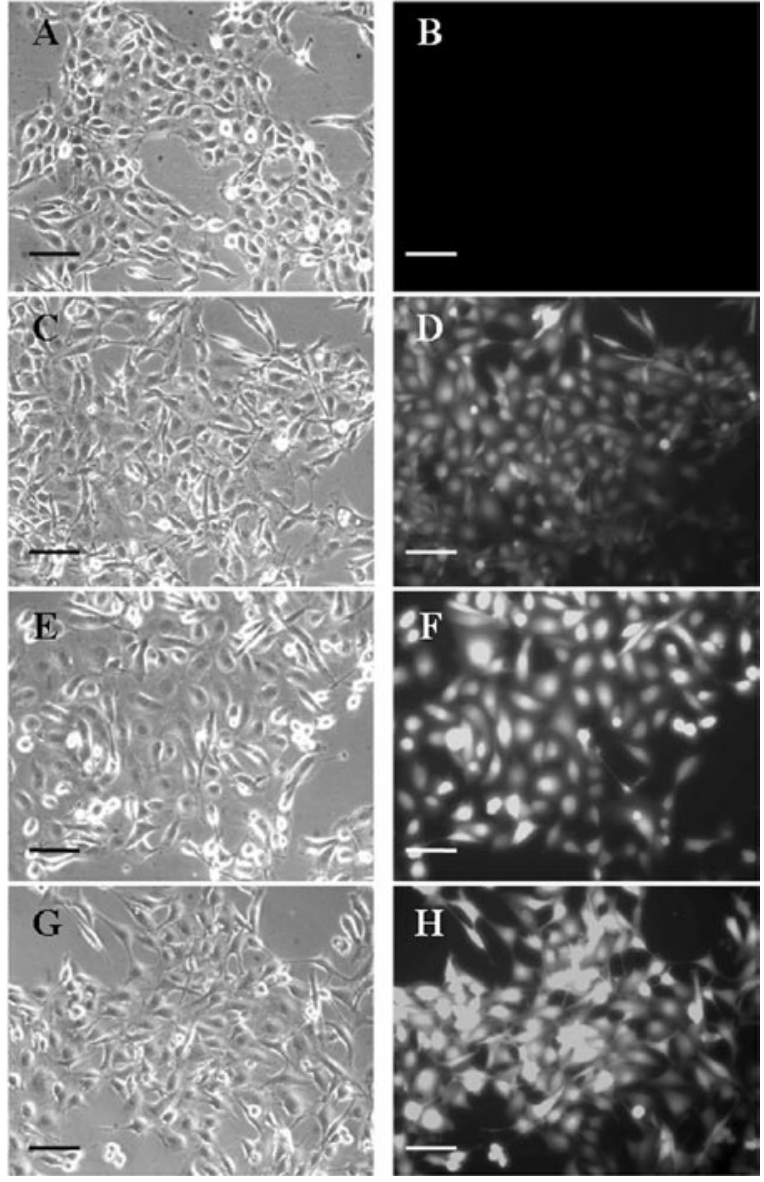

Figure 2. Cell morphology and expression of GFP by ACCS sublines. ACCS cell sublines were established using in vivo selection and transfection with a GFP vector. ACCS-GFP (C and D) is a GFP-expressing subline of ACCS (A and B). ACCS-T was established after two cycles of in vivo selection (E and F), and ACCS-T GFP is its GFP-expressing subline ( $\mathrm{G}$ and $\mathrm{H})$. ACCS-M GFP (I and J) was established in a second round of in vivo selection with ACCS-T GFP. Phase-contrast (A, C, E, G and I) and GFP (B, D, F, H and J) images are shown. Scale bars indicate $100 \mu \mathrm{m}$.

higher tumorigenic clones by repeatedly recovering cells in vitro and transplanting them into the tongues of nude mice. Consequently, the subline ACCS-T GFP exhibiting high tumorigenicity (100\% incidence) was obtained through this in vivo selection process.

For the ACCS-T GFP cells, tumors measuring 120-180 $\mathrm{mm}^{3}$ in the tongue were observed in 16 out of 16 mice, 4-7 weeks following injection. Although the doubling times of ACCS-T
GFP and ACCS GFP cells were similar at 19.5 and $21.1 \mathrm{~h}$, respectively, their in vivo growth rates clearly differed. No metastasis was observed in the nude mice injected with ACCS-GFP cells. The site of metastasis was clearly visualized as a green spot under excitation light (Fig. 1D and F). At 5-7 weeks, when the primary tumor reached a size of $100 \mathrm{~mm}^{3}$, autopsies showed that the ACCS-T GFP cells had metastasized to the submandibular lymph nodes (50\% incidence, Fig. 1D) and lungs (31.3\% incidence, Fig. $1 \mathrm{~F}$ and Table 1). Using two more rounds of in vivo selection, we obtained and selected another subline, ACCS-M GFP, which had greater metastatic ability than ACCS-T GFP (Fig. 2). All 9 mice injected with ACCS-M had lymph node metastases, while 6 of the 9 had lung metastases (Table I and Fig. 1C-F). The histological features of ACCS-T GFP and ACCS-M GFP tumors were similar to the solid pattern of AdCC (Fig. 3). We also examined the expression of salivary gland tumor-specific antigens immunohistochemically (data not shown). Several groups of cells in the tumor masses derived from ACCS-T GFP and ACCS-M GFP expressed calponin, $\alpha$-SMA, c-kit and p63, which suggested the existence of myoepithelial cells of salivary gland carcinoma.

Analysis of invasive and metastatic characteristics of highly metastatic AdCC cells by in vitro invasion assay. To evaluate the invasive and metastatic characteristics of the ACCS cell lines, we performed a newly established invasion assay using fibroblast-containing collagen type I, which mimics cancer mesenchymal tissue, as described previously (14). In this assay, cancer cells are allowed to form highly concentrated tumor nests, and subsequent cell migration through the ECM, which closely mimics the conditions found in vivo, is measured. After tumor cell clusters were formed by each cell line, ACCS-GFP cells showed tight primary nests and ring-like structures with homophilic intercellular adhesion (Fig. 4A). In contrast, the ACCS-M GFP cells had clearly migrated from the cancer nests (Fig. 4C). Evaluation of the invasion status revealed a significant induction of cancer cell dissemination by ACCS-M GFP cells, which was $\sim 2.5$-fold greater than the ACCS-GFP cells (Fig. 4D). Taken together, these results suggest that ACCS-M GFP cells have lost the homophilic intercellular adhesion, thus inducing cancer cell dissemination from cancer nests.

Identifying the most significant biological activities supporting metastasis by mining DNA microarray data. To understand
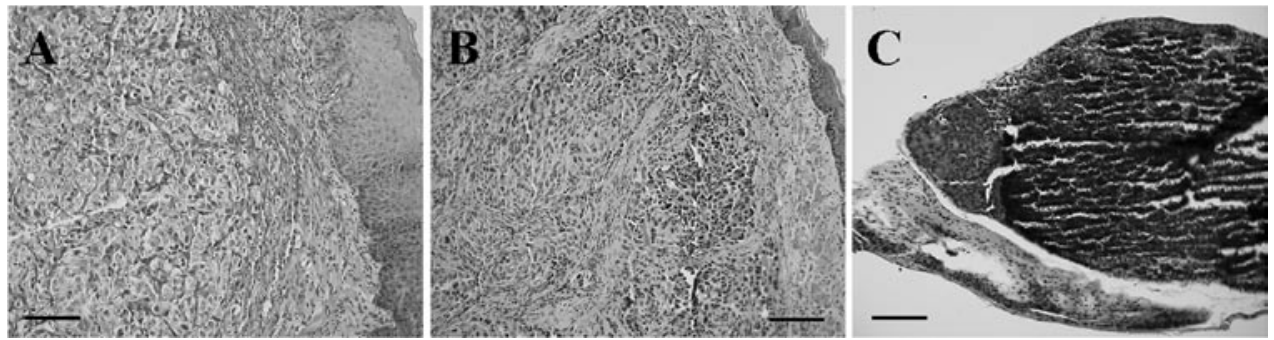

Figure 3. Histopathology of primary tumors and metastatic lymph nodes. After the mice were sacrificed, the tongue and metastatic lymph nodes were removed and fixed with $2 \%$ paraformaldehyde/PBS. Paraffin-embedded tissue sections (5- $\mu$ m thickness) were stained with hematoxylin and eosin. (A) ACCS-T GFP and (B) ACCS-M GFP-derived tumors. (C) Metastatic lymph node in a mouse inoculated with ACCS-M GFP cells. Scale bars indicate $100 \mu$ m. 

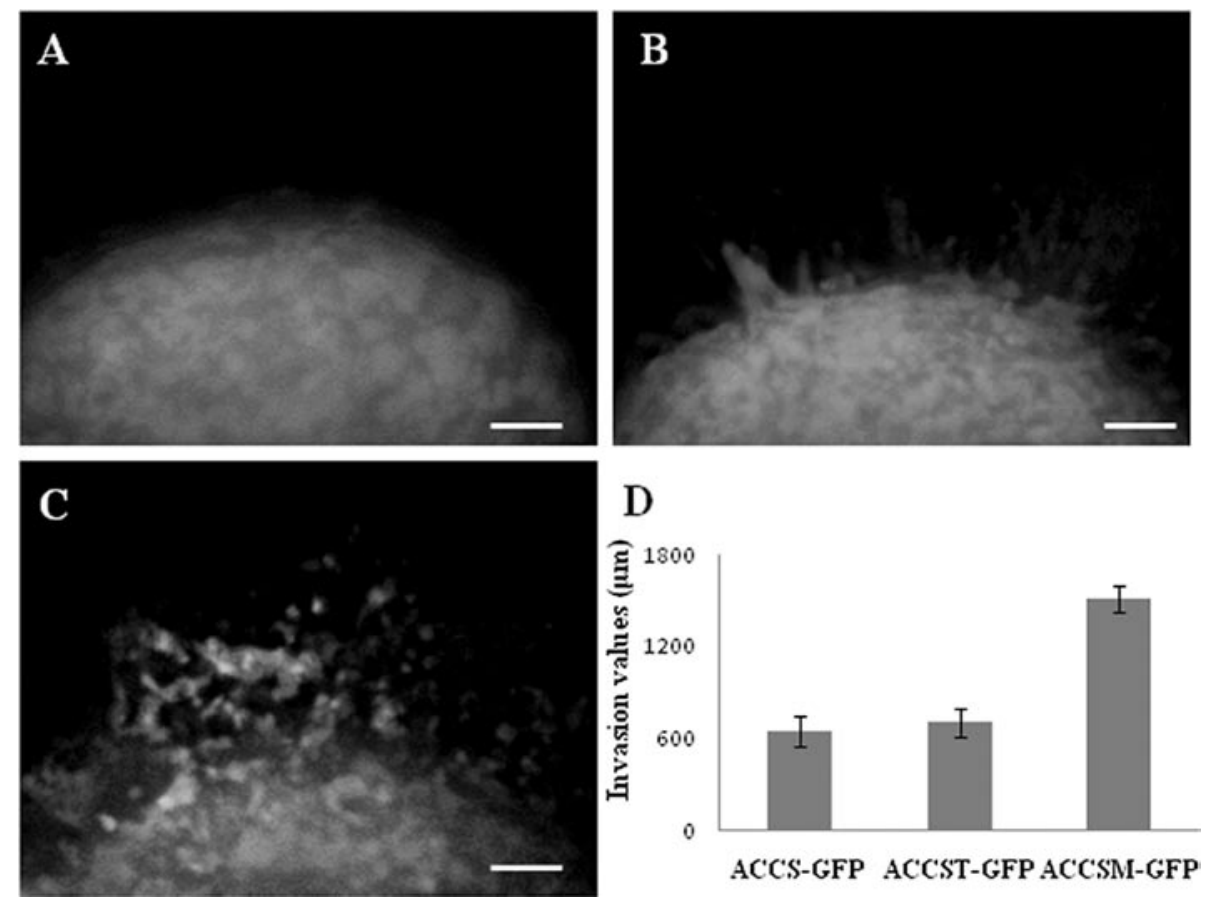

Figure 4. Evaluation of tumor dissemination from primary nests by an in vitro invasion assay. ACCS-GFP (A), ACCS-T GFP (B) and ACCS-M GFP cells (C) were analyzed with a newly developed invasion assay. Cancer cells were visualized by excitation of GFP with broad-spectrum UV light. Scale bars indicate $100 \mu \mathrm{m}$. (D) The evaluation of invasive value was carried out as described in Materials and methods. All experiments were performed at least in triplicate, and representative results are shown.

the differences between metastatic and non-metastatic cells at the molecular level, we performed DNA microarray analysis using parental ACCS-GFP and ACCS-M GFP cells. Total RNA extracted from these cell lines was hybridized to the Affymetrix GeneChip HG-U133A plus 2.0 array, which contained 47,000 transcripts, including 38,500 known genes. After normalization, the data were filtered using the Student's t-test $(\mathrm{P}<0.01)$ and a threshold of 3 -fold change in expression between ACCS-GFP and ACCS-M GFP, resulted in a list of significant genes containing 352 known transcripts. Table II shows the top 20 up- and down-regulated genes from the significant genes list. Notably, a significant up-regulation of cell-signaling molecules was detected in ACCS-M GFP cells (underlined words).

We then performed a GeneSpring gene ontology analysis. The top $20\left(\mathrm{P}<10^{-7}\right)$ genes that significantly altered biological processes as selected by GeneSpring GX are listed in Table III. Genes involved in 'organismal physiological processes' were identified as the most significant biological function in ACCS-M GFP cells, and the top ten up- and down-regulated genes are shown in Table IV. Most strikingly, the expression of connexin 43 (gap junction protein $\alpha 1$ ) was highly up-regulated (140-fold) in the ACCS-M GFP cells. It should also be noted that ECM genes, such as fibronectin were down-regulated in this group. Events related to cell adhesion (three categories) and signaling (three categories) dominated the top 20 list of significantly altered biological processes (Table III). The findings from the DNA analysis strongly support the results of the in vitro invasion assay as well as those from our previous observations of marked differences in the expression of adhesion molecules and adhesion-related signaling in AdCC cell lines compared to SCC cell lines $(11,12)$. Consequently, we focused on the analysis of genes related to cell adhesion, several of which were among the most significantly up- and down-regulated genes summarized in Table II (words in bold). In particular, the significant down-regulation of cell adhesion molecules, such as cadherins and integrin subunits was observed. The loss of ECM proteins was also significant. In contrast, other cadherins (cadherin 18 and 19) were strongly up-regulated.

Alteration of the expression pattern of E-cadherin, integrins and vimentin on tumorigenic and metastatic cells. As altered epithelial cell adhesion-related gene expression in the highly metastatic ACCS-M GFP cell line clearly indicated that these cells differed from the parental ACCS in epithelium identity, we examined whether ACCS-M GFP cells changed the expression of adhesion molecules during the establishment process using immunoblotting (Fig. 5A). Our analysis revealed that E-cadherin was lost only in ACCS-M GFP cells. Similar findings were observed for $\alpha 1, \alpha 2, \alpha 3, \alpha 4, \alpha 6$ and $\beta 1$ integrins in ACCS-M GFP cells, while $\alpha 4$ integrin was relatively stable in all of the established ACCS sublines. The increased expression of integrins $\alpha 3$ and $\alpha 6$ was observed in the tumorigenic ACCS-T GFP cells as opposed to the ACCS-GFP cells. In contrast, vimentin, a mesenchymal cell marker protein, was up-regulated in the ACCS-M GFP cells. The expression level of connexin 43 was also significantly up-regulated in the ACCS-M GFP cells, as indicated in the DNA microarray analysis.

We then fractionated the cell lysate into cell membrane and cytosolic fractions using an ultracentrifuge fractionation 
Table II. The 20 most significant up- and down-regulated genes in highly metastatic ACC-M GFP cells.

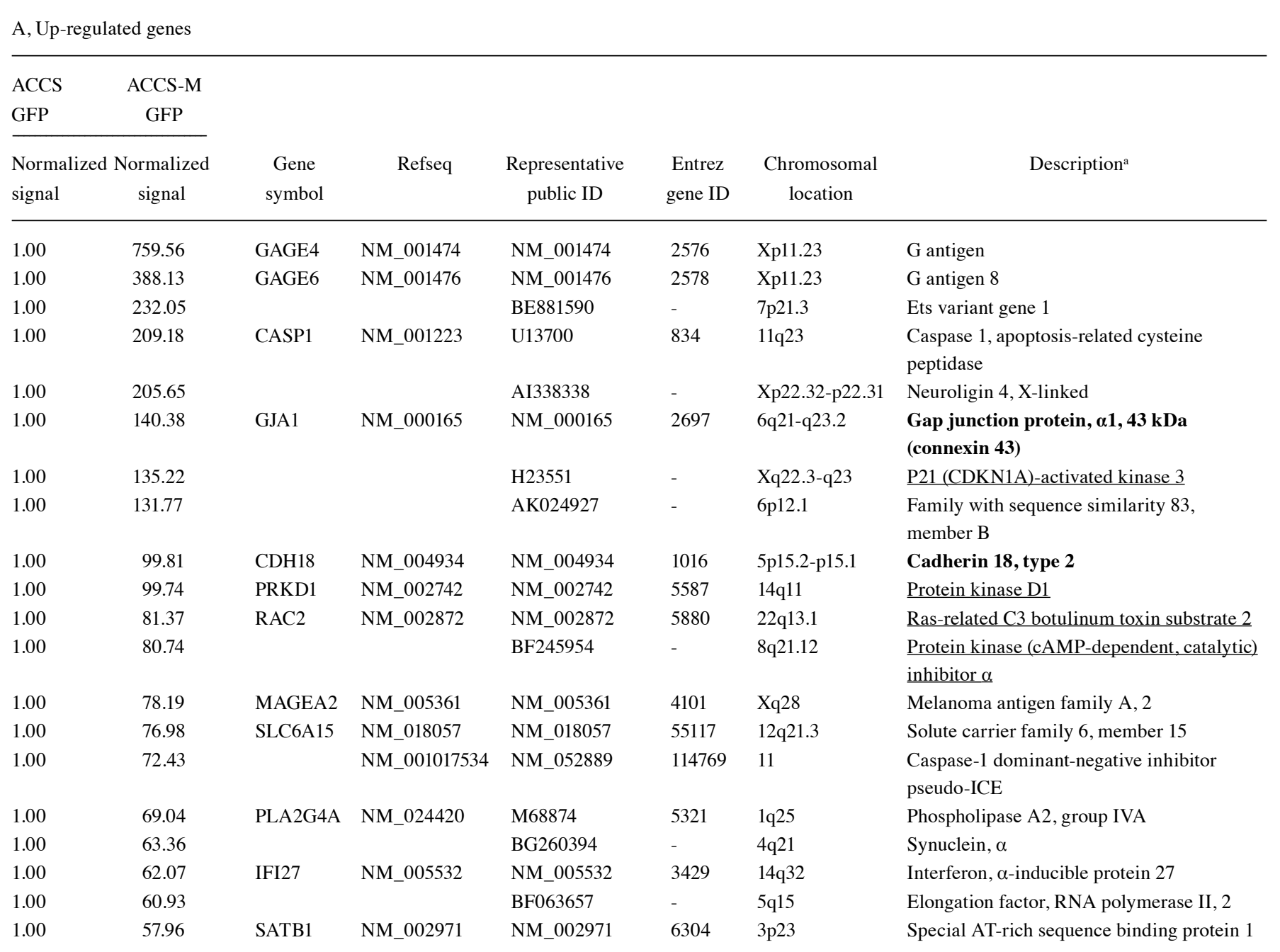

B, Down-regulated genes

\begin{tabular}{|c|c|c|c|c|c|c|c|}
\hline 1.00 & 0.01 & CD69 & NM_00178 & L07555 & 969 & 12p13-p12 & CD69 molecule \\
\hline 1.00 & 0.01 & & & AW014927 & & $8 q 21.3-q 22.1$ & Calbindin $1,28 \mathrm{kDa}$ \\
\hline 1.00 & 0.01009 & $\mathrm{CDH} 3$ & NM_001793 & NM_001793 & 1001 & $16 \mathrm{q} 22.1$ & Cadherin 3, type 1, P-cadherin \\
\hline 1.00 & 0.0141 & & & AW183188 & & $3 q 26.1$ & $\begin{array}{l}\text { Intraflagellar transport } 80 \text { homolog } \\
\text { (Chlamydomonas) }\end{array}$ \\
\hline 1.00 & 0.01511 & & & AI765437 & & $16 \mathrm{q} 12.2$ & Calpain, small subunit 2 \\
\hline 1.00 & 0.01605 & SPAG11 & NM_016512 & NM_058206 & 10407 & $8 \mathrm{p} 23-\mathrm{p} 22$ & Sperm associated antigen 11 \\
\hline 1.00 & 0.01687 & IL1R2 & NM_004633 & U64094 & 7850 & $2 q 12-q 22$ & Interleukin 1 receptor, type II \\
\hline 1.00 & 0.01718 & & & AA504346 & & $19 q 13.4$ & Zinc finger protein 154 (pHZ-92) \\
\hline 1.00 & 0.0182 & LAMA3 & NM_000227 & NM_000227 & 3909 & $18 \mathrm{q} 11.2$ & Laminin, $\alpha 3$ \\
\hline 1.00 & 0.01956 & CDH1 & NM_004360 & NM_004360 & 999 & $16 \mathrm{q} 22.1$ & Cadherin 1, type 1, E-cadherin \\
\hline 1.00 & 0.02049 & & & AI796169 & & $10 \mathrm{p} 15$ & GATA binding protein 3 \\
\hline 1.00 & 0.02066 & & & ВC020680 & & $1 q 32$ & Complement factor H-related 1 \\
\hline 1.00 & 0.02183 & & & AW468885 & & & Chromosome $\mathrm{Y}$ open reading frame $15 \mathrm{~A}$ \\
\hline 1.00 & 0.02224 & GATM & NM_001482 & NM_001482 & 2628 & $15 \mathrm{q} 21.1$ & Glycine amidinotransferase \\
\hline 1.00 & 0.02232 & & & AI612095 & & $17 q 22-q 23$ & SMAD specific E3 ubiquitin protein ligase 2 \\
\hline 1.00 & 0.02358 & SLC25A21 & NM_030631 & NM_030631 & 89874 & $14 q 11.2$ & Solute carrier family 25, member 21 \\
\hline 1.00 & 0.0244 & & & AI632216 & & $4 q 25-q 27$ & $\begin{array}{l}\text { Dual adaptor of phosphotyrosine and } \\
\text { 3-phosphoinositides }\end{array}$ \\
\hline 1.00 & 0.02598 & LACE1 & NM_145315 & NM_145315 & 246269 & $6 q 22.1$ & Lactation elevated 1 \\
\hline 1.00 & 0.02635 & & & AI935915 & & $16 \mathrm{p} 11.2$ & SH3-binding domain kinase 1 \\
\hline 1.00 & 0.02657 & SLC27A2 & NM_003645 & NM_003645 & 11001 & $15 \mathrm{q} 21.2$ & Solute carrier family 27, member 2 \\
\hline
\end{tabular}

aWords in bold indicate cell motility-related genes, while underlined words indicate signaling-related genes. 
Table III. Most significant biological processes in highly metastatic ACCS-M GFP cells revealed by DNA microarray analysis.

\begin{tabular}{|c|c|c|c|c|c|}
\hline Category & Genes in category & $\begin{array}{l}\% \text { of Genes } \\
\text { in category }\end{array}$ & $\begin{array}{l}\text { Genes in list } \\
\text { in category }\end{array}$ & $\begin{array}{c}\% \text { of Genes in list } \\
\text { in category }\end{array}$ & P-value \\
\hline 1. Organismal physiological process & 2567 & 15.610 & 660 & 24.510 & $3.64 \mathrm{E}-40$ \\
\hline 2. Cell communication & 4888 & 29.720 & 1030 & 38.250 & $1.67 \mathrm{E}-25$ \\
\hline 3. Defense response & 1270 & 7.722 & 341 & 12.660 & 4.03E-23 \\
\hline 4. Response to biotic stimulus & 1320 & 8.026 & 344 & 12.770 & $5.70 \mathrm{E}-21$ \\
\hline 5. Immune response & 1140 & 6.931 & 304 & 11.290 & $4.02 \mathrm{E}-20$ \\
\hline 6. Response to external biotic stimulus & 765 & 4.651 & 210 & 7.798 & $1.62 \mathrm{E}-15$ \\
\hline 7. Response to pest, pathogen or parasite & 755 & 4.591 & 207 & 7.687 & $3.01 \mathrm{E}-15$ \\
\hline 8. Response to external stimuli & 1012 & 6.153 & 259 & 9.618 & $7.44 \mathrm{E}-15$ \\
\hline 9. G-protein coupled receptor protein signaling pathway & 840 & 5.107 & 223 & 8.281 & $1.08 \mathrm{E}-14$ \\
\hline 10. Cell surface receptor linked signal transduction & 1652 & 10.040 & 382 & 14.180 & 4.09E-14 \\
\hline 11. Cell-cell signaling & 744 & 4.524 & 195 & 7.241 & 2.04E-12 \\
\hline 12. Signal transduction & 3897 & 23.690 & 779 & 28.930 & 4.10E-12 \\
\hline 13. Response to stimuli & 2715 & 16.510 & 568 & 21.090 & $5.23 \mathrm{E}-12$ \\
\hline 14. Cell adhesion & 933 & 5.673 & 230 & 8.541 & $1.60 \mathrm{E}-11$ \\
\hline 15. Neurophysiological process & 837 & 5.089 & 208 & 7.724 & $7.50 \mathrm{E}-11$ \\
\hline 16. Humoral immune response & 218 & 1.325 & 74 & 2.748 & $1.37 \mathrm{E}-10$ \\
\hline 17. Response to wounding & 551 & 3.350 & 145 & 5.384 & $1.14 \mathrm{E}-09$ \\
\hline 18. Regulation of organismal physiological process & 215 & 1.307 & 70 & 2.599 & $3.25 \mathrm{E}-09$ \\
\hline 19. Sensory perception & 509 & 3.095 & 130 & 4.827 & $5.68 \mathrm{E}-08$ \\
\hline 20. Homophilic cell adhesion & 171 & 1.040 & 56 & 2.079 & $9.45 E-08$ \\
\hline
\end{tabular}

Rows in bold indicate cell adhesion- and cell signaling-related processes.

procedure. Notably, $\beta$-catenin, a partner protein of E-cadherin, was found only in the membrane fractions of ACCS-GFP and ACCS-T GFP cells, while $\beta$-catenin was also found in the cytosolic fraction of ACCS-M GFP cells (Fig. 5B).

\section{Discussion}

Invasive growth and distant metastasis are characteristic clinical features of AdCC compared to other malignant tumors of the oral cavity, and represent significant barriers to the treatment of the disease. We have been studying the mechanisms of invasion and metastasis of AdCC using in vitro invasion models $(12,17)$. However, metastasis is a complicated process that is difficult to mimic in vitro. Therefore, it was important to establish a spontaneous metastasis model for AdCC using orthotopic implantation. However, we found that the cultured AdCC cell line was merely tumorigenic in the nude mouse. This is the first study to establish a spontaneous metastasis model of AdCC using orthotopic implantation and tumorigenic cell lines with metastatic potential from an AdCC cell line. The pathological features of the primary tumor sites were similar to those of solid-type AdCC, with the expression of calponin, $\alpha$-smooth muscle actin, and p63 demonstrating that the tumor was in fact AdCC. The primary tumor of the metastatic clone (ACCS-M GFP) was also more solid than that of the tumorigenic clone (ACCS-T GFP). These features resemble the clinical characteristics of solid-type AdCC, which is more invasive and metastatic than the other types of AdCC. The results of the in vitro invasion assay showed a significant induction of cancer cell dissemination from the primary tumor nests in the ACCS-M GFP cell line. As this assay evaluates E-cadherin-mediated tumor cell dissemination (14), these data support the invasive and metastatic character of the primary implanted tumor of ACCS-M GFP in vivo and suggest that molecular alteration of cell adhesion molecules occurs on ACCS-M GFP cell surfaces.

One explanation for the success of in vivo selection and changes in metastatic character is the inherent genetic heterogeneity of malignant cells. As malignant cells contain subpopulations with different biological characters, during in vivo selection, a subpopulation with metastatic potential could come to dominate the population. It is also possible that genetic alteration leading to increases in metastatic potential spontaneously occurs in vivo or in vitro, as ACCS-M GFP was established from a primary tumor and not from metastatic lymph nodes and was passaged in vitro. A similar transformation of an AdCC cell line has been reported during serial passage in vitro (18). Therefore, the identification of the critical genes related to metastasis will be important for understanding AdCC metastasis.

The DNA microarray analysis of human tumor specimens to identify metastasis-related genes has been reported in several types of cancer, including head and neck cancer (19-23). Genes identified from these analyses are typically involved in cell migration, invasion, angiogenesis, proliferation and chemotaxis. Although a profile of these genes would be useful for the diagnosis and prediction of metastasis, it is difficult to translate the results from DNA microarray data due to tumor heterogeneity and the difficulty of conducting 
Table IV. Most significant gene alterations related to organismal physiological processes in highly metastatic ACCS-M GFP cells. ${ }^{\mathrm{a}}$

A, Top ten up-regulated genes

\begin{tabular}{|c|c|c|c|c|c|c|c|}
\hline $\begin{array}{l}\text { ACCS } \\
\text { GFP }\end{array}$ & $\begin{array}{l}\text { ACCS-M } \\
\text { GFP }\end{array}$ & & & & & & \\
\hline $\begin{array}{l}\text { Normalized } \\
\text { signal }\end{array}$ & $\begin{array}{l}\text { Normalized } \\
\text { signal }\end{array}$ & $\begin{array}{l}\text { Gene } \\
\text { symbol }\end{array}$ & Refseq & $\begin{array}{l}\text { Representative } \\
\text { public ID }\end{array}$ & $\begin{array}{c}\text { Entrez } \\
\text { gene ID }\end{array}$ & $\begin{array}{l}\text { Chromosomal } \\
\text { location }\end{array}$ & Description $^{\mathrm{a}}$ \\
\hline 1.00 & $\underline{140.38}$ & GJA1 & NM_000165 & NM_000165 & 2697 & $6 \mathrm{q} 21-\mathrm{q} 23.2$ & $\begin{array}{l}\text { Gap junction protein, } \alpha 1,43 \mathrm{kDa} \\
\text { (connexin 43) }\end{array}$ \\
\hline 1.00 & 62.07 & IFI27 & NM_005532 & NM_005532 & 3429 & $14 \mathrm{q} 32$ & Interferon, $\alpha$-inducible protein 27 \\
\hline 1.00 & 55.78 & BST2 & NM_004335 & NM_004335 & 684 & $19 \mathrm{p} 13.2$ & Bone marrow stromal cell antigen 2 \\
\hline 1.00 & 33.15 & IL7 & NM_000880 & NM_000880 & 3574 & $8 q 12-q 13$ & Interleukin 7 \\
\hline 1.00 & 26.95 & HTR2C & NM_000868 & NM_000868 & 3358 & $\mathrm{Xq} 24$ & 5-Hydroxytryptamine (serotonin) receptor $2 \mathrm{C}$ \\
\hline 1.00 & 18.79 & IFITM1 & NM_003641 & NM_003641 & 8519 & $11 \mathrm{p} 15.5$ & $\begin{array}{l}\text { Interferon induced transmembrane protein } 1 \\
(9-27)\end{array}$ \\
\hline 1.00 & 15.49 & APOBEC $3 \mathrm{G}$ & NM_021822 & NM_021822 & 60489 & $22 \mathrm{q} 13.1$ & $\begin{array}{l}\text { Apolipoprotein B mRNA editing enzyme, } \\
\text { catalytic polypeptide-like } 3 \mathrm{~F}\end{array}$ \\
\hline 1.00 & 15.09 & $\mathrm{NR} 3 \mathrm{C} 2$ & NM_000901 & NM_000901 & 4306 & $4 \mathrm{q} 31.1$ & $\begin{array}{l}\text { Nuclear receptor subfamily } 3 \text {, group C, } \\
\text { member } 2\end{array}$ \\
\hline 1.00 & 14.74 & BLNK & NM_013314 & NM_013314 & 29760 & $10 \mathrm{q} 23.2-\mathrm{q} 23.33$ & B-cell linker \\
\hline 1.00 & 14.58 & CLEC2B & NM_005127 & CA447397 & 9976 & $12 \mathrm{p} 13-\mathrm{p} 12$ & C-type lectin domain family 2 , member B \\
\hline
\end{tabular}

B, Top ten down-regulated genes

\begin{tabular}{llllllll}
\hline 1.00 & 0.01 & OLR1 & NM_002543 & AF035776 & 4973 & 4973 & Oxidized low density lipoprotein receptor 1 \\
1.00 & $\underline{0.06}$ & FN1 & NM_002026 & X02761 & 2335 & 2335 & Fibronectin 1 \\
1.00 & 0.06 & SERPINA1 & NM_000295 & NM_000295 & 5265 & 5265 & $\begin{array}{l}\text { Serpin peptidase inhibitor, clade A, } \\
\text { member 1 }\end{array}$ \\
1.00 & 0.07 & GATA3 & NM_001002295 & BC003070 & 2625 & 2625 & GATA binding protein 3 \\
1.00 & 0.13 & LAT2 & NM_014146 & AF257135 & 7462 & 7462 & Neutrophil cytosolic factor 1 \\
1.00 & 0.16 & F11R & NM_016946 & AF191495 & 50848 & 50848 & F11 receptor \\
1.00 & 0.18 & SLC1A3 & NM_004172 & NM_004172 & 6507 & 6507 & Solute carrier family 1, member 3 \\
1.00 & 0.18 & C3 & NM_000064 & NM_000064 & 718 & 718 & Complement component 3 \\
1.00 & 0.2 & INHBA & NM_002192 & M13436 & 3624 & 3624 & Inhibin, $\beta A$ \\
1.00 & 0.2 & F2RL1 & NM_005242 & NM_005242 & 2150 & 2150 & Coagulation factor II (thrombin) \\
& & & & & & receptor-like 1 \\
\hline
\end{tabular}

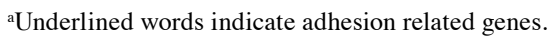

functional analyses. The establishment of an animal metastasis model, as described here, allows for the functional analysis of acquired genes and their products. Translational research using DNA microarrays in an AdCC metastatic model is particularly important given the characteristic invasive and metastatic behaviors of AdCC. Similarly, other research groups have reported the use of cell lines from breast cancer animal models for DNA microarray analysis (24). In this study, we compared the expression profiles of ACCS-GFP and ACCS-M GFP cells on a DNA microarray, as this should reflect the elements responsible for AdCC tumorigenicity and metastasis, and observed a total of 352 highly significant genes with fold changes of $>3$. Moreover, $57 \%$ had fold changes of $>5$. This large number of significant genes resulted in significant overlap $\left(\mathrm{P}<10^{-7}\right)$ with listed biological processes and functions as defined by GeneSpring. The most significant biological processes were organismal and physiological processes (Table III). Of the genes in this group, the expression of connexin 43, an abundant gap junction protein, was increased the most significantly (170-fold) in ACCS-M GFP cells. The association of connexin 43 with cancer metastasis is controversial, as the loss of this protein is often observed in cancer tissues $(25,26)$. However, the increased connexin 43 expression in lymph node metastases has been reported in breast and prostate cancers $(27,28)$. The role of connexin 43 in metastasis is also supported by its ability to mediate heterocellular gap junctional communication, which enhances cancer cell diapedesis, the migration of fibroblasts and vascular endothelial cells through mesenchymal tissues, and the extravasation of cancer cells $(28,29)$. In addition, connexin 43 is also up-regulated in micrometastasis and tumor vasculature, and markedly so in tumor cell-endothelial cell 

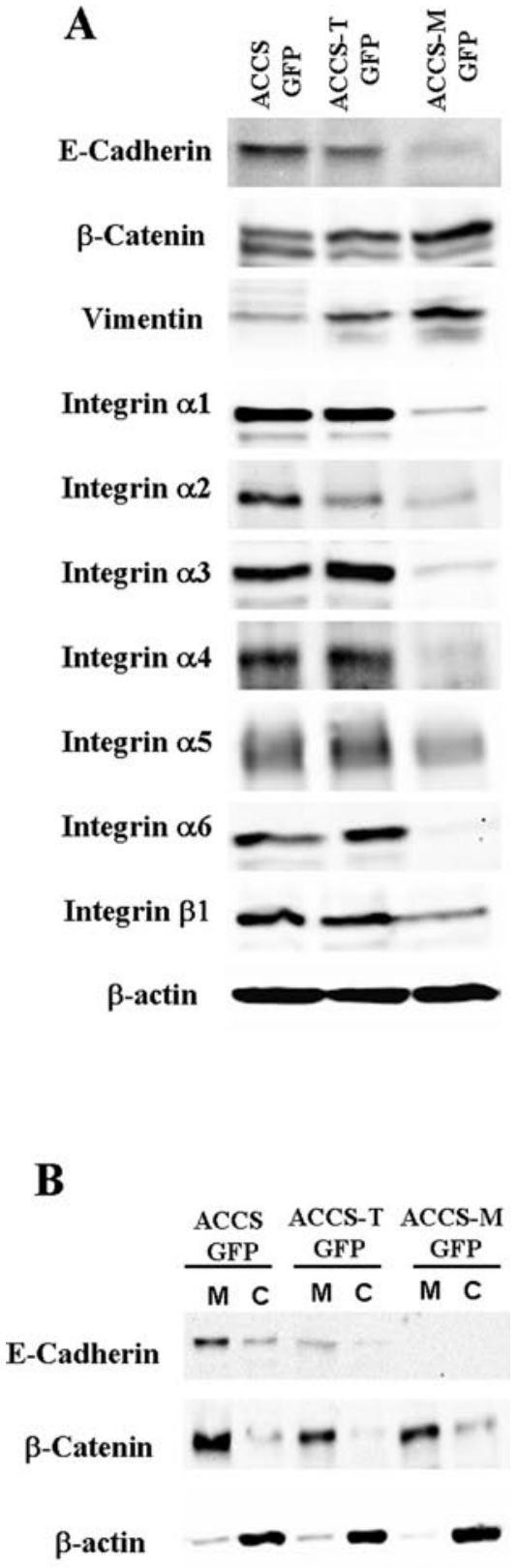

Figure 5. Highly metastatic cells show EMT-like alterations and downregulation of integrins compared to the parental ACCS cells. After the ACCS-GFP, ACCS-T GFP and ACCS-M GFP cells were cultured for $24 \mathrm{~h}$ on culture dishes, cell lysates were prepared and resolved using 10\% SDSPAGE. (A) The levels of EMT-related biomarkers and integrins were detected by immunoblotting with antibodies against the indicated proteins. (B) Protein translocation after subcellular fractionation was examined using immunoblotting with antibodies against the indicated proteins. All experiments were performed at least in triplicate, and representative results are shown.

contact areas, whether in pre-existing vessels or in newly formed tumor vessels (30). These studies strongly suggest that connexin 43 accelerates tumor extravasation and adhesion to endothelial cells at distant sites.

Our DNA microarray data mining analysis provides important information for understanding the biological behavior of metastatic AdCC cells. Not surprisingly, processes related to cell adhesion were identified as significantly altered biological processes in the metastatic cells. In contrast to the up-regulation of the gap junction protein connexin 43, significant down-regulation of cell adhesion molecules, such as E-cadherin was also observed. The loss of typical epithelial cell markers, such as E-cadherin, and the gain of mesenchymal markers, such as vimentin, are hallmarks of epithelial-mesenchymal transition (EMT) (31-33), and were found significantly more often in the metastatic AdCC cells (ACCS-M GFP). There is also evidence showing that EMT is involved in a de-differentiation process in epithelial tumor progression, which serves to interrupt cell-to-cell contact in tumors in a homocellular fashion, allowing for the dissemination of single cells from the primary site (34). Therefore, EMT could be an important phenotypic alteration promoting non-metastatic tumor transition to metastatic carcinoma $(34,35)$. As E-cadherin transduces signals through its partner protein $\beta$-catenin, which binds to E-cadherin and transduces various signals to cell-signaling molecules, the loss of E-cadherin does not only disrupt cell-to-cell contact, but also affects more significant signaling events. For example, the proteolytic disruption of E-cadherin or the induction of E-cadherin repressors disrupts E-cadherin/ $\beta$-catenin complexes at the plasma membrane, which strongly enhances cytoplasmic $\beta$-catenin and target gene transcription leading to cell proliferation or EMT/migration $(36,37)$. Our observations of the down-regulation of E-cadherin and increased expression of vimentin and cytoplasmic $\beta$-catenin in the metastatic cell line suggest the involvement of EMT in ACCS metastasis and are consistent with other studies of head and neck and breast cancers (38).

We also found indications of altered integrin expression following tumorigenic and metastatic cell line establishment. In tumorigenic ACCS-T GFP cells, integrin expression was higher than in the parental ACCS cells, whereas the loss of integrin expression was found in the metastatic ACCS-M GFP cells. It is reasonable to suggest that tumorigenicity requires strong ECM and cell-to-cell binding, while metastasis requires detachment from the matrix or cells. Of note, $\alpha 5$ integrin expression was stable in all the ACCS sublines. An important role of $\alpha 5 \beta 1$ integrin in tumorigenicity or organ-specific metastasis has been reported in certain tumor cell types (39-41). For example, in a spontaneous metastasis model involving Chinese hamster ovary (CHO) cells expressing integrin $\alpha 5 \beta 1$ at various levels, kidney metastasis did not develop in the $\mathrm{CHO}$ cells expressing high levels of $\alpha 5$ integrin (41). These findings suggest that there is a specific level of $\alpha 5$ expression on tumor cells that leads to metastasis. However, it is not clear how $\alpha 5 \beta 1$ integrin affected the tumorigenicity or metastasis of the ACCS cell lines in our study.

In summary, we established an AdCC orthotopic implantation animal metastasis model by generating AdCC cell sublines with tumorigenic and metastatic potential. DNA microarray analysis of this metastasis model provided valuable information on the specific behaviors of metastatic versus non-tumorigenic cells. The loss of E-cadherin and integrin, indicative of EMT, is a putative event for AdCC metastasis and the induction of tumor cell dissemination from the primary tumor site. Furthermore, the significant up-regulation of connexin 43 mediates heterocellular contact and induces cell migration through the mesenchymal tissue and extravasation. Alterations in integrin expression could also be 
crucial for the tumorigenicity of AdCC. The mouse metastasis model established here should prove to be a useful tool for AdCC metastasis research and clinical treatment trials, including further translational research with DNA microarrays, particularly the functional analyses of acquired genes.

\section{Acknowledgements}

This study was supported by a Grant-in-Aid (no. 20390517) from the Ministry of Education, Culture, Sports, Science, and Technology of Japan (to K.S. and T.S.).

\section{References}

1. Rapidis AD, Givalos N, Gakiopoulou H, Faratzis G, Stavrianos SD, Vilos GA, Douzinas EE and Patsouris E: Adenoid cystic carcinoma of the head and neck. Clinicopathological analysis of 23 patients and review of the literature. Oral Oncol 41: 328-335, 2005.

2. Tomich CE: Adenoid cystic carcinoma. In: Surgical pathology of the salivary glands. Ellis GL, Auclair PL and Gnepp DR (eds.) WB Saunders Company, Philadelphia, pp333-349, 1991.

3. Ellis GL and Auclair PL: Adenoid cystic carcinoma. Vol. 17, 3rd edition. Armed Forces Institute of Pathology, Washington DC, 1996.

4. Ampil FL and Misra RP: Factors influencing survival of patients with adenoid cystic carcinoma of the salivary glands. J Oral Maxillofac Surg 45: 1005-1010, 1987.

5. Liotta LA: Tumor invasion and metastases-role of the extracellular matrix: Rhoads Memorial Award lecture. Cancer Res 46: $1-7,1986$

6. Chambers AF, Groom AC and MacDonald IC: Dissemination and growth of cancer cells in metastatic sites. Nat Rev Cancer 2: 563-572, 2002.

7. Fidler IJ: The pathogenesis of cancer metastasis: the 'seed and soil' hypothesis revisited. Nat Rev Cancer 3: 1-6, 2003.

8. Fidler IJ: The organ microenvironment and cancer metastasis. Differentiation 70: 498-505, 2002

9. Shirasuna K, Saka M, Hayashido Y, Yoshioka H, Sugiura T and Matsuya T: Extracellular matrix production and degradation by adenoid cystic carcinoma cells: participation of plasminogen activator and its inhibitor in matrix degradation. Cancer Res 53: $147-152,1993$

10. Shirasuna K, Watatani K, Furusawa H, Saka M, Morioka S, Yoshioka $\mathrm{H}$ and Matsuya T: Biological characterization of pseudocyst-forming cell lines from human adenoid cystic carcinomas of minor salivary gland origin. Cancer Res 50 : 4139-4145, 1990

11. Li CY, Abu Ali S, Sugiura T, Shiratsuchi T, Sasaki M and Shirasuna K: Integrin expression and migration of adenoid cystic carcinoma cells in response to basement membrane components. Oral Sci Int 1: 22-29, 2004.

12. Abu Ali S, Sugiura T, Takahashi M, Shiratsuchi T, Ikari T, Seki K, Hiraki A, Matsuki R and Shirasuna K: Expression of the urokinase receptor regulates focal adhesion assembly and cell migration in adenoid cystic carcinoma cells. J Cell Physiol 203 410-419, 2005.

13. He RG, Qiu WL and Zhou XJ: The establishment of Acc-2 and Acc-3 and their morphological observation. J West China Stomatol 6: 1-4, 1988.

14. Abe M, Sugiura T, Takahashi M, Ishii K, Shimoda M and Shirasuna K: A novel function of CD82/KAI-1 on E-cadherinmediated homophilic cellular adhesion of cancer cells. Cancer Lett 266: 163-170, 2008.

15. Behrmann I, Smyczek T, Heinrich PC, Schmitz Van de Leur H, Komyod W, Giese B, Muller Newen G, Haan S and Haan C: Janus kinase (Jak) subcellular localization revisited: the exclusive membrane localization of endogenous Janus kinase 1 by cytokine receptor interaction uncovers the Jak.receptor complex to be equivalent to a receptor tyrosine kinase. J Biol Chem 279: 35486-35493, 2004.

16. Hou JC, Shigematsu S, Crawford HC, Anastasiadis PZ and Pessin JE: Dual regulation of Rho and Rac by p120 catenin controls adipocyte plasma membrane trafficking. J Biol Chem 281: 23307-23312, 2006.
17. Seki K, Ishii K, Sugiura T, Takahashi $M$ and Inoue $Y$ and Shirasuna K: An adenoid cystic carcinoma cell line possessing high metastatic activity has high $\mathrm{NF}-\kappa \mathrm{B}$ activation in response to TNF- $\alpha$. Oral Sci Int 2: 36-44, 2005.

18. Hashitani S, Noguchi K, Manno Y, Moridera K, Takaoka K, Nishimura N, Kishimoto H, Sakurai K and Urade M: Changes of histological and biological features by serial passages in a human adenoid cystic carcinoma line transplantable in nude mice. Oncol Rep 13: 607-612, 2005.

19. Patel KJ, Pambuccian SE, Ondrey FG, Adams GL and Gaffney PM: Genes associated with early development, apoptosis and cell cycle regulation define a gene expression profile of adenoid cystic carcinoma. Oral Oncol 42: 994-1004, 2006.

20. Kupferman ME, Patel V, Sriuranpong V, Amornphimoltham P, Jasser SA, Mandal M, Zhou G, Wang J, Coombes K, Multani A, Pathak S, Silvio Gutkind J and Myers JN: Molecular analysis of anoikis resistance in oral cavity squamous cell carcinoma. Oral Oncol 43: 440-454, 2007.

21. Zhang X, Su L, Pirani AA, Wu H, Zhang H, Shin DM, Gernert KM and Chen ZG: Understanding metastatic SCCHN cells from unique genotypes to phenotypes with the aid of an animal model and DNA microarray analysis. Clin Exp Metastasis 23: 209-222, 2006.

22. Muthusamy V, Duraisamy S, Bradbury CM, Hobbs C, Curley DP, Nelson B and Bosenberg M: Epigenetic silencing of novel tumor suppressors in malignant melanoma. Cancer Res 66: 11187-11193, 2006.

23. Rohan S, Tu JJ, Kao J, Mukherjee P, Campagne F, Zhou XK, Hyjek E, Alonso MA and Chen YT: Gene expression profiling separates chromophobe renal cell carcinoma from oncocytoma and identifies vesicular transport and cell junction proteins as differentially expressed genes. Clin Cancer Res 12: 6937-6945, 2006.

24. Kluger HM, Chelouche Lev D, Kluger Y, McCarthy MM, Kiriakova G, Camp RL, Rimm DL and Price JE: Using a xenograft model of human breast cancer metastasis to find genes associated with clinically aggressive disease. Cancer Res 65: 5578-5587, 2005.

25. Conklin CM, Bechberger JF, Macfabe D, Guthrie N, Kurowska EM and Naus CC: Genistein and quercetin increase connexin 43 and suppress growth of breast cancer cells. Carcinogenesis 28: 93-100, 2006.

26. Torres LN, Matera JM, Vasconcellos CH, Avanzo JL, Hernandez Blazquez FJ and Dagli ML: Expression of connexins 26 and 43 in canine hyperplastic and neoplastic mammary glands. Vet Pathol 42: 633-641, 2005.

27. Kanczuga Koda L, Sulkowski S, Lenczewski A, Koda M, Wincewicz A, Baltaziak $M$ and Sulkowska M: Increased expression of connexins 26 and 43 in lymph node metastases of breast cancer. J Clin Pathol 59: 429-433, 2006.

28. Miekus K, Czernik M, Sroka J, Czyz J and Madeja Z: Contact stimulation of prostate cancer cell migration: the role of gap junctional coupling and migration stimulated by heterotypic cell-to-cell contacts in determination of the metastatic phenotype of Dunning rat prostate cancer cells. Biol Cell 97: 893-903, 2005.

29. Pollmann MA, Shao Q, Laird DW and Sandig M: Connexin 43 mediated gap junctional communication enhances breast tumor cell diapedesis in culture. Breast Cancer Res 7: R522-R534, 2005.

30. Elzarrad MK, Haroon A, Willecke K, Dobrowolski R, Gillespie MN and Al-Mehdi AB: Connexin-43 upregulation in micrometastases and tumor vasculature and its role in tumor cell attachment to pulmonary endothelium. BMC Med 6: 20, 2008.

31. Putz E, Witter K, Offner S, Stosiek P, Zippelius A, Johnson J, Zahn R, Riethmuller G and Pantel K: Phenotypic characteristics of cell lines derived from disseminated cancer cells in bone marrow of patients with solid epithelial tumors: establishment of working models for human micrometastases. Cancer Res 59: 241-248, 1999.

32. Kim JB, Islam S, Kim YJ, Prudoff RS, Sass KM, Wheelock MJ and Johnson KR: N-Cadherin extracellular repeat 4 mediates epithelial to mesenchymal transition and increased motility. J Cell Biol 151: 1193-1206, 2000.

33. Kiemer AK, Takeuchi K and Quinlan MP: Identification of genes involved in epithelial-mesenchymal transition and tumor progression. Oncogene 20: 6679-6688, 2001.

34. Thompson EW, Newgreen DF and Tarin D: Carcinoma invasion and metastasis: a role for epithelial-mesenchymal transition? Cancer Res 65: 5991-5995, 2005. 
35. Tarin D, Thompson EW and Newgreen DF: The fallacy of epithelial mesenchymal transition in neoplasia. Cancer Res 65: 5996-6000, 2005

36. Huber MA, Kraut $\mathrm{N}$ and Beug H: Molecular requirements for epithelial-mesenchymal transition during tumor progression. Curr Opin Cell Biol 17: 548-558, 2005.

37. Thiery JP: Epithelial-mesenchymal transitions in tumour progression. Nat Rev Cancer 2: 442-454, 2002.

38. Harigopal M, Berger AJ, Camp RL, Rimm DL and Kluger HM: Automated quantitative analysis of E-cadherin expression in lymph node metastases is predictive of survival in invasive ductal breast cancer. Clin Cancer Res 11: 4083-4089, 2005.

39. Schiller JH and Bittner G: Loss of the tumorigenic phenotype with in vitro, but not in vivo, passaging of a novel series of human bronchial epithelial cell lines: possible role of an alpha 5/ beta 1-integrin-fibronectin interaction. Cancer Res 55: 6215-6221, 1995.
40. Qian F, Zhang ZC, Wu XF, Li YP and Xu Q: Interaction between integrin alpha(5) and fibronectin is required for metastasis of B16F10 melanoma cells. Biochem Biophys Res Commun 333: 1269-1275, 2005

41. Tani N, Higashiyama S, Kawaguchi N, Madarame J, Ota I, Ito Y, Ohoka Y, Shiosaka S, Takada Y and Matsuura N: Expression level of integrin alpha 5 on tumour cells affects the rate of metastasis to the kidney. Br J Cancer 88: 327-333, 2003. 